\title{
Respecting the deal: how to manage co-opetitive actors in open innovation
}

\begin{abstract}
Platforms like E-bay allow product seekers and providers to meet and exchange goods. On the same way in open innovation, as defined by Chesbrough [1], an enterprise can collect ideas from outside the company. But on E-bay, the seeker can return the product if it does not correspond to the expectations, since Ebay is the third-party actor in charge of assuring that the agreement between seekers and providers will be respected. So who does provide the same service for what concerns open innovation, where specifications might not fully defined? In this paper we shall describe the business model of an organizational structure to support the elicitation and respect of agreements between actors, who have conflicting interests but that gain from cooperating together. The concepts of the model will be illustrated to derive a set of propositions and a simple example will illustrate one of its possible instantiations. The description of our first evaluation phase shall find place at the end.
\end{abstract}

\section{Introduction: problem identification}

In this paper we deal with co-opetition in open innovation. According to Brandenburger and Nalebuff [2] a co-opetition game can be defined by means of five components, i.e. Players, Added Values, Rules, Tactics and Scope.

On what concern the players, one can refer to the adaptation of Michael Porter's five forces made by Nalebuff and Branderburger (op.cit., p.30) to quote the four key roles that relate to the main actor: customers, suppliers, complementors and competitors. The authors list a set of strategies to motivate new players to enter the game, and West and Gallegher [3] refers to expectancy theory to suggest the reasons that push enterprise to contribute in open source software developments.

The assessment of the added values of actors raises two issues: how to calculate such value and how to increase it. In this sense Simard and West [4] name a set of metrics, while West and Gallegher (op.cit.) list three major challenges of open innovation, i.e. maximizing returns to internal innovation, incorporating external innovations and motivating spillovers.

The rules in this kind of game deals with the risk of not addressing properly the challenges previously mentioned. One can mention West and Gallegher (op.cit.) to underline the risk of wrong coordination between actors, which Doz and Hamel [5] address by suggesting the design of an interface between actors. We also recall the work of Simard and West (op.cit.) and their definitions of different ties (formal 
VS informal and deep VS wide). In particular, the deep and wide ties address the risk of exploitation of the future outcomes of the innovation.

The inventors of the term "co-opetition" list three different tactics to deal with information asymmetry between actors. Referring to open innovation Doz and Hamel (op. cit.) assess the shift in the kind of relationship between actors, while West and Gallagher (op.cit.) describes four business models used by software companies to capitalize their contributions to open sources programs.

On the matter of scope, following the indications of Vanhaverbeke [6]) open innovation can be studied at the intra-organizational and firm level, as well as at the dyad and inter-organizational level. In our work we shall consider a network of actors which deals with each other. Indeed we consider the legal boundaries as hard to be defined, since different business units in the same enterprise could be submitted to different regulations and deal with each other by means of internal service level agreements.

Referring to what has been said so far, from an agency theory point of view coopetition is the best strategy for those game in which asymmetry of information does not allow complete trust between actors, but yet there is a partial common good that can be achieved only by cooperating.

Our contention is that co-opetition works for projects where there is a high risk of failure, which a single actor is not ready to stand, and there is a promise of high potential returns, high enough for the actor to be contented even if it receives only a part of it. Indeed mentioned by Wagner and Layton [7], there are two kinds of risk: the unrewarded one, which is a sort of cost to be paid in advance to enter the game, and a rewarded one, which is the promise of potential returns. We believe that co-opetition aims at sharing the unrewarded risk. This would aim to reduce what Khan and Blair [8] defines as the total cost of failure. On the other hand this form of partnership requires coordination, which the transaction cost theory links to transaction costs.

In this study we will propose a framework that supports management decisions concerning the information system - intended as "the interaction between the information technology and the social setting"([9]) - to achieve the best trade-off between trust and control, in order to achieve what Cox et al. [10] refers as confidence at a minimum cost.

A large amount of literature has been previously focused on information technologies to automatically perform negotiation between enterprises; hence we will rather focus on the risk management process in the context of regulatory compliance, i.e. the definition of the objectives of the partnership, the assessment of the risks of failure and enforcement of a set of controls.

We believe that a viable tactic for an actor should be to define rules that would shape the game in an advantageous way, and we will follow Hegel's [11] suggestion and we will focus on ways to shape the shared platform to exchanges information between actors. 
In doing so we will seek to find an equilibrium between the different requirements of all stakeholders, in order to achieve a solution that is sustainable over the time, i.e. which pushes all actors to not quit the game.

Following what has been said so far, our research question is the following:

\section{How to support risk management in multi-actor contexts of information system regulatory compliance, such as co-opetition in open innovation, in order to achieve efficiency, consistency and sustainability?}

The rest of the paper proceeds as it follows. Section 2 lists and motivates the requirements we set for the solution we wanted to obtain. Section 3 illustrates our design and it describes the development process of the design. Section 4 presents the design in action by mean of an example. Section 5 is dedicated to the evaluations of the design that we have already done, together with those tests that will follows. Section 6 ends the papers with discussions and conclusions.

\section{The objectives of the solution}

We shall assume that the unrewarded risk between co-opetitive actors will be shared by means of a formal agreement concerning the service that each actor shall deliver. In this sense one can identify the set of risks that occurs while signing a contract. Referring to the three categories of risk in signing a contract described by Willcocks et al. [12]), we assess that a consistent number of works have been published on the first two sets of risk, namely the contextual risks and the ones related to the design of the contract.

According to what said so far our solution shall address the post-contract issues. Hence the information system to be in place shall include the required capabilities and skills to manage the relationship between co-opetitive actors; it shall include activities required to perform the required business and technical changes; it shall rely on proved standards based on best practices; it shall have a system to manage power between co-opetitive actors; and it shall support the monitoring of the supplier performance without forgetting the informal ties previously mentioned.

Referring to our research question, to obtain efficiency the solution in place should include an information system that reduces manual work and combines functionalities to allow data monitoring to assure respect of the SLA and information to support the rules management. A list of capabilities of the user of the information system should be given. To achieve consistency such rules management should be represented at a strategic level, in a standard way. On what concerns the sustainability of the solution, the information system should be able to evolve in time, while the compliance function itself should have a function that allows it to adapt to environment change in a profitable way. 


\section{Design and development}

We decided to start with the most general case and to consider the compliance function as a business unit, which could be positioned within or without the reference companies, and we defined its business model accordingly, adopting the guidelines presented in Osterwalder and Pigneur [13].

Proposition 1: the proposed model allows it to obtain a consistent solution, since it manages at the strategic level the rules to enforce.

\begin{tabular}{|c|c|c|c|c|c|}
\hline $\begin{array}{l}\text { Partner } \\
\text { Network }\end{array}$ & Key Activities & \multicolumn{2}{|c|}{$\begin{array}{c}\text { Value } \\
\text { Proposition }\end{array}$} & $\begin{array}{l}\text { Customer } \\
\text { Relationship }\end{array}$ & $\begin{array}{l}\text { Customer } \\
\text { Segments }\end{array}$ \\
\hline \multirow[t]{3}{*}{$\begin{array}{l}\text { Sourcing } \\
\text { strategy } \\
\text { Global } \\
\text { Infrastructure } \\
\text { Vertical } \\
\text { Best-of-Breed } \\
\text { Horizontal } \\
\text { Solutions } \\
\text { benchmarks }\end{array}$} & $\begin{array}{l}\text { Platform management } \\
\text { Viewpoints integrations } \\
\text { Options analysis } \\
\text { Monitoring } \\
\text { Regulations update } \\
\text { Service Provisioning: } \\
\text { IT Leadership (R) } \\
\text { Architecture development (K) } \\
\text { Business enhancement (KR) } \\
\text { Technology advancement (R) } \\
\text { Service management (M) } \\
\text { Technical management (KR) }\end{array}$ & \multirow{2}{*}{\multicolumn{2}{|c|}{$\begin{array}{l}\text { Value Prop 1: } \\
\text { Requirements } \\
\text { elicitations } \\
\text { Value Prop 2: } \\
\text { Requirements } \\
\text { enforcement monitoring } \\
\text { Value Prop 3: } \\
\begin{array}{l}\text { Requirements } \\
\text { enforcement }\end{array} \\
\text { Value Prop 4: } \\
\text { Access to cash } \\
\text { opportunities }\end{array}$}} & $\begin{array}{l}\text { Suppliers } \\
\text { relationship } \\
\text { Deep VS wide } \\
\text { Formal VS informal }\end{array}$ & \multirow[t]{3}{*}{$\begin{array}{l}\text { Customer Segment 1: } \\
\text { Internal Seekers } \\
\text { Customer Segment 2: } \\
\text { External Seekers } \\
\text { Customer Segment 3: } \\
\text { Internal Solvers } \\
\text { Customer Segment 4: } \\
\text { External Solvers }\end{array}$} \\
\hline & Key Resources & & & $\begin{array}{c}\text { Distribution } \\
\text { Channels }\end{array}$ & \\
\hline & $\begin{array}{l}\text { SLA } \\
\text { Platform } \\
\text { Competencies: } \\
\text { Behavioral; Business; Technical }\end{array}$ & & & $\begin{array}{l}\text { Excellence Team } \\
\text { Best-practices sharing } \\
\text { group } \\
\text { Virtual team } \\
\text { Centralized team }\end{array}$ & \\
\hline \multicolumn{3}{|c|}{ Cost Structure } & \multicolumn{3}{|c|}{ Revenue Flows } \\
\hline \multicolumn{2}{|c|}{$\begin{array}{l}\text { Platform management \& development } \\
\text { Solutions benchmark } \\
\text { Acquisition of Seekers and Solvers }\end{array}$} & & \multicolumn{3}{|c|}{$\begin{array}{l}\text { Network effect: Free viewpoints integrations } \\
\text { Network effect: Free access to regulations update } \\
\text { Revenue Flow 1: Fee on options analysis } \\
\text { Revenue Flow 2: Fee on solutions benchmark }\end{array}$} \\
\hline
\end{tabular}

Fig. 1: Business model for the holistic compliance management function

We designed our solution as having a double-sided business model [14], i.e. basing its value proposition on the alignment of different customer segments, which gain from the network effect of converging in the same platform. In this sense we listed the four customer segments according to two dimensions: those that seek for a service against those that provide it, and those that belong to the same company as the business function against those who do not.

Four value propositions have been deduced from a work on compliance presented last year at ItAIS [15]: on what concerns the solution seeker, support should be delivered regarding the requirements elicitation and the monitoring of requirements enforcement. On the other hand, the solution providers shall be supported in 
accessing to cash opportunity and deciding which applications use to enforce the regulatory requirements. The relationships between the seekers and providers follow the idea of ties illustrated in Simard and West (op.cit.).

Regarding the distribution channel one could see this business unit as a center of excellence, which can take the three shapes presented by Cullen [16]: a bestpractices sharing group, a virtual team or a centralized service. According to the shape, the distribution channels offered by the platform will increase their complexity.

From what said so far, the revenue flows appear composed by four components related to the four customer segments. One can assume that some components might imply a fee to be accessed, while other components might be free to access, to attract users in the platform and gain from network effects.

On what concerns the key activities, beyond those related to the platform management, we took inspiration from the existing work of Cox and De Jong [17] and Joha [18] in outsourcing regarding the so-called "retained organization", i.e. the portion of the company that is kept to assure the interface with the new suppliers. According to the authors five activities should be in place:

1. The contract management: it involves a support on everything concerning the design and management of new formal agreements between the solution seeker and the providers.

2. The service management: refers to technical problems experienced by the solution seekers, which have to be solved by inter-mediator, who contacts the provider.

3. The technological advancement: this refers to the support to the projects management that the provider has in place to deliver the solution.

4. The business advancement: it deals with support on business process analysis and design, and process management.

5. Architecture development: this usually implies consulting activities regarding the development of the architecture of the solution seeker, by producing the requirements for the solution provider.

Proposition 2: the mentioned activities of the business unit allow it to reduce the post-contractual risk, since they support the required business and technical changes, and they monitor the solution provider.

Proposition 3: the use of standard approach like IPW for the activities of the business unit allows it to reduce the post-contractual risk.

The key resources include the service level agreement, the platform (for an example of its functionalities one can refer to the recent work of Bonazzi and Pigneur [19]), and the capabilities of the employees of the business unit. In this sense a large list of capabilities can be found in Cox and De Jong (op.cit.) and Joha (op.cit.), which class them in three groups: technical, business and behavioral. 
Proposition 4: the mentioned capabilities of the business unit allow it to reduce the post-contractual risk, since it manages the relationship between co-opetitive actors.

Proposition 5: the proposed platform allows it to reduce the post-contractual risk, since it manages the power relationship between co-opetitive actors.

Proposition 6: the proposed platform allows it to reduce the cost, since it performs most of the tasks automatically.

The partners of the center of excellence are also its customers and the cost structure reflects that: the major costs involve the platform development and management and the acquisition of new solution seekers and providers, to gain from network effects.

Proposition 7: the proposed approach allows it to obtain a sustainable solution, since its cash flows are greater than the cost.

\section{Instantiation of the artifact}

We applied our design to an existing case of open innovation, i.e. Innocentive. In this case the co-opetitive actors are the problem solution seekers, who need a punctual solution, and the problem solvers, who have the required skills to deliver the solution. The solvers get profit from their knowledge, so they will try to solve the problem while explaining the solving process as less as possible, while the seekers will try to minimize their dependency from an external source.

Both actors are external to the business unit. In this sense we shall have only two customer segments, two value proposition and two revenue flows (the reader shall note the access to problems is free to gain new platform users). The distribution channel is Internet and Incentive can be defined as a centralized service offered to the users.

Regarding the key activities, one can find the platform management, while the activity 1 and 2 of our list can be deduced by the list of services offered. The key resources are the platform, the set of contracts between seekers and solvers, and the three groups of capabilities, which can be deduced by the requirements for job applicants. The cost structure is not given. Yet one can suppose that in this case, with the data available, propositions 2, 4 and 7 would find a confirmation.

\section{Evaluation}

In this first stage we have decided to evaluate our model by means of experts' opinion. We have already presented our design to a small panel of experts to collect their opinions concerning its efficiency, consistency and sustainability. 
Starting from the feedback received a second version of the model has been developed and a survey has been prepared to let the experts rate each proposition of ours in a five-point Likert scale. The new data collection will be done on a larger scale (some 50 experts) in the following months.

\section{Discussion and conclusions}

The presented work addressed a part of the literature regarding the link between open innovation, co-opetition and risk management, which has been only partially covered so far by the literature. By looking for a suitable solution design we crossed different domains, i.e. open innovation, outsourcing and more in general enterprise networks governance. Our goal was to start defining the IT managerial, methodological and technological capabilities and processes aiming at answering our research question. In doing so we hope to rise the interest of Information System researchers in this direction of investigation, since we believe that such issues fall into the nomological net defined by Benbasat and Zmud [20].

The business model we obtain is still a work in progress, but in its final form it will aim at being a pattern for those companies, which find themselves having to address the problem of co-opetition in open innovation.

In this stage of development we have decided to rely on experts' opinion to evaluate our design, since it is the evaluation approach that assured us the largest amount of data in a shorter amount of time. In the next iteration we shall apply the model to real cases by mean of a qualitative study.

\section{References}

1. Chesbrough H.W. (2003). The era of open innovation. MIT Sloan Management Review, 44, (3): 35-41.

2. Brandenburger A.M., Nalebuff B.J. Co-Opetition : A Revolution Mindset That Combines Competition and Cooperation : The Game Theory Strategy That's Changing the Game of Business. 1st ed., Broadway Business, 1997.

3. West J., Gallagher S. (2006). Challenges of open innovation: the paradox of firm investment in open-source software. $R \& D$ Management, 36, (3):319-331.

4. Simard C., West J. (2006). Knowledge networks and geographic locus of innovation. In Chesbrough H.W., Vanhaverbeke W., West, J (eds.). Open innovation: researching a new paradigm, Oxford University Press, USA, 2006.

5. Doz Y.L., Hamel G. Alliance advantage: The art of creating value through partnering. Harvard Business School Press, 1998.

6. Vanhaverbeke W. (2006). The inter-organizational context of open innovation. In Chesbrough H.W., Vanhaverbeke W., West, J (eds.). Open innovation: researching a new paradigm, Oxford University Press, USA, 2006.

7. Wagner S., Layton M. (2007). The two faces of risk. Available at: http://www.deloitte.com 
8. Kahn R., Blair B.T. Information Nation: Seven Keys to Information Management Compliance, Aiim International, 2004.

9. Lee A.S. (1999). Inaugural Editor's Comments. MIS Quarterly, 23, (1).

10. Cox R.A., Marriott I., Seabrook D. Trust and Control: The Key to Optimal Outsourcing Relationships, Gartner Inc., 2003.

11. Hagel J. (2002). Leveraged Growth: Expanding Sales Without Sacrificing Profits. Harvard Business Review, 80, (10):68-79.

12. Willcocks L.P., Lacity M.C., Kern T. (1999). Risk mitigation in IT outsourcing strategy revisited: longitudinal case research at LISA. Journal Of Strategic Information Systems, 8, (3):285-314.

13. Osterwalder A., Pigneur Y., Tucci C.L. (2005). Clarifying business models: Origins, present, and future of the concept. Communications of the association for Information Systems, 16, (1):1-25.

14. Eisenmann T., Parker G., Van Alstyne M.W.(2006). Strategies for two-sided markets. Harvard business review, 84, (10):92-101.

15. Bonazzi R., Hussami L., Pigneur Y. (2008). Compliance management is becoming a major issue in IS design. In ITAIS 2008 Proceedings. Paris: Springer.

16. Cullen A. Current Practices For IT Centers Of Excellence (CoEs). Forrester Research Inc., 2008.

17. Cox R., De Jong B. The Right Retained Team is Critical for Successful Outsourcing. Gartner Inc., 2005.

18. Joha A. The Retained Organization after IT outsourcing. The Design of its Organizational Structure. Faculty of Technology, Policy and Management. Delft University of Technology, 2003.

19. Bonazzi R., Pigneur Y. (2009). Compliance Management in Multi-actor Contexts. In GRCISO9 Proceedings. Amsterdam. Available at http://ceur-ws.org/Vol459/paper7.pdf

20. Benbasat, I., Zmud, R. W. (2003). The identity crisis within the is discipline: Defining and communicating the discipline's core propertie. MIS Quarterly, 27, (2):183-194 